Maria Carolina Foss

\title{
Análise Jurídica da PromoÇÃo da InOVAÇÃo TeCNOLógica no SeTOR BRASIleiro de TECNOLOGIAS DA INFORMAÇÃO E COMUNICAÇÃO
}

\author{
Dissertação de Mestrado \\ Orientador: Prof. Dr. Newton Silveira
}

Universidade de São Paulo

Faculdade de Direito São Paulo 2013 
Maria Carolina Foss

\section{Análise Jurídica da PromoÇÃo da InOVAÇão TeCnológica No Setor Brasileiro de TeCNOLOGias DA INFORMAÇÃO E COMUNICAÇÃO}

Dissertação depositada como requisito parcial para obtenção de título de Mestre em Direito, em conformidade com Regimento da Pós-Graduação da USP, Resolução $\mathrm{n}^{\mathrm{o}} 5473 / 2008$, Portaria CPGFDUSP $n^{\circ}$ 5/2011 e Resolução FD/PÓS n ${ }^{\circ} 1 / 2002$.

Universidade de São Paulo

Faculdade de Direito

São Paulo

2013 
FOSS, Maria Carolina. Análise jurídica da promoção da inovação tecnológica no setor brasileiro da tecnologia da informação e comunicação. Maria Carolina Foss. São Paulo: [s.n.], 2013, 173 pp.

Orientador: Prof. Dr. Newton Silveira

Área de concentração: Direito Comercial

Pós-graduação stricto sensu Mestrado em Direito

1. Inovação tecnológica 2. Propriedade intelectual. Pós-Graduação stricto sensu - Faculdade de Direito da Universidade de São Paulo. 
Banca Examinadora: 


\section{RESUMO}

A promoção da inovação tecnológica é um desafio para o aumento da competitividade da indústria brasileira. O setor de tecnologias da informação e comunicação (TICs) é um importante celeiro de novas tecnologias e suas criações intelectuais são passíveis de proteção pelas normas de propriedade industrial (e.g. patentes), direitos autorais (e.g. software) e segredo de negócio ou industrial. No Brasil, o setor de TICs, anteriormente designado setor de informática, obteve tratamento prioritário nos programas governamentais de incentivo ao desenvolvimento tecnológico nacional. Contudo, as empresas brasileiras de TICs ainda não são consideradas inovadoras em comparação à concorrência estrangeira. A Lei no 10.973/2004, também conhecida como Lei de Inovação, dispõe sobre instrumentos jurídicos para a articulação de interesses do setor privado e das Instituições Científicas e Tecnológicas (ICTs) que são órgãos e entidades da administração pública com a missão de executar atividades de pesquisas básica e aplicada, seja de caráter científico ou com a finalidade de desenvolvimento de novas tecnologias. A hipótese de pesquisa desta dissertação é de que os acordos celebrados entre as ICTs e o setor privado estão concentrados nos objetos da transferência de tecnologia ou no licenciamento de uso de criações desenvolvidas pela ICT, que limitados ao regime do direito público, não são eficazes para promoção da inovação tecnológica no setor de TICs. Esta dissertação propõe: (i) analisar o arcabouço normativo do Sistema Nacional da Inovação Tecnológica; (ii) analisar os programas governamentais de estímulo ao desenvolvimento tecnológico do setor de informática brasileiro; (iii) examinar o papel da proteção da propriedade intelectual do software na promoção da inovação tecnológica; (iv) investigar as deficiências na articulação dos interesses de ICT e setor privado, conforme os instrumentos jurídicos previstos na Lei de Inovação; e (v) sugerir proposições para contornar os problemas identificados. Utilizou-se uma metodologia segmentada no estudo normativo das leis aplicáveis ao Sistema Nacional da Inovação Tecnológica e à proteção da propriedade intelectual do software e na análise dos arranjos jurídicos enunciados na Lei de Inovação, a partir dos resultados da Pesquisa de Inovação Tecnológica do Instituto Brasileiro de Geografia e Estatística (PINTEC 2008/IBGE) e das informações das ICTs, consolidadas pelo Ministério de Ciência, Tecnologia e Inovação (MCTI) e pelos próprios Núcleos de Inovação Tecnológica (NITs) das ICTs selecionadas nesta pesquisa (sendo elas, USP, UNICAMP, UFMG e UFRJ) cujos dados disponíveis apresentaram semelhança entre si. Concluiu-se com a comprovação da hipótese de que os instrumentos jurídicos utilizados por ICT e empresários são ineficazes para promoção da inovação tecnológica no setor de TICs. Por fim, destacou-se o conhecimento como o desafio para promover o processo inovador no setor brasileiro de TICs. Dentro do propósito do aproveitamento do conhecimento acumulado nas ICTs, a ampliação do conceito de ICT para incorporar as instituições privadas, como previsto nos Projetos de Lei do "Código Nacional de Ciência Tecnologia e Inovação" no $n^{\circ}$ 2.177/2011 e no 619/2011 em tramitação no Congresso Nacional, assim como a participação de capital privado na reformulação da figura da sociedade de propósito específico, prevista no art. $5^{\circ}$ da Lei de Inovação, são possíveis soluções para contornar os problemas identificados nesta dissertação.

Palavras-chave: Inovação tecnológica. Propriedade intelectual. Indústria de software. 


\begin{abstract}
The promotion of technological innovation is a challenge for the increase of competitiveness of the Brazilian industry. The information and communication technologies (ICT) industry is an important source of new technologies and its intellectual creations may be protected under industrial property rights (e.g. patents), copyrights (e.g. software) and trade secret or industry secret laws. In Brazil the ICT industry, previously known as the computer industry, received a priority treatment in the national governmental incentive programs for the development of technology. However, Brazilian ICT companies are not considered innovative in comparison with their foreign competitors. The Brazilian Law \#10,973/2004, also known as Brazilian Innovation Law, establishes legal means for the orchestration of interests of the private sector and those of Scientific and Technological Institutions (STIs), which are agencies and public entities whose dedicated to basic and applied research, whether having scientific purpose or aiming at the creation of new technologies. This research hypothesis is that the agreements entered by the STIs and the private sector aim technology transfers or the license of use of the STIs' creations and those agreement governed by public law are not effective for the promotion of technological innovation in the ICT industry. This study proposes to: $(i)$ review the legal framework of the National System of Innovation; (ii) analyze the governmental programs created to stimulate the technological development of the Brazilian computer industry; (iii) review the role of the intellectual property protection of software for the promotion of technological innovation; (iv) inquire the deficiencies in the articulation of the interests of STI and private sector according to the agreements provided on the Brazilian Innovation Law and (v) suggest alternatives to overcome the identified problems. A segmented methodology was used in the exam of the laws applicable to the National System of Innovation and the laws of intellectual property protection of the software and the analysis of the agreements entered under the Brazilian Innovation Law provisions, considering the results of the Research of Technological Innovation of the Instituto Brasileiro de Geografia e Estatística (PINTEC 2008/IBGE) and the STIs' consolidated information by the Ministério de Ciência, Tecnologia e Inovação (MCTI) and also with the Centers of Innovation Technology (NITs) of the STIs studied in this masters dissertation (which are, USP, UNICAMP, UFMG and UFRJ) whose available data were similar. The study's conclusion confirms the hypothesis that the agreements entered by STIs and private companies are ineffective to stimulate the technological innovation in the ICT industry. Lastly the knowledge was highlighted as a challenge to promote the innovative process in the Brazilian ICT sector. Within the purpose of using the STIs' accumulated knowledge, expanding the concept of STIs to incorporate private institutions, as provided into the Legislative Bill of the National Code of Science and Technological Innovation $\# 2,177 / 2011$ and \#619/2011 in discussion in the National Congress, as well as the participation of private capital in reformulating the concept of the special purpose vehicle provided under Article 5 of Brazilian Innovation Law are possible solutions to overcome the problems identified in this study.
\end{abstract}

Keywords: Technological Innovation. Intellectual Property. Software industry. 


\section{LiSTA De Siglas e Abreviaturas}

ABDI Agência Brasileira de Desenvolvimento Industrial

ANPEI Associação Nacional de Pesquisa e Desenvolvimento das Empresas Inovadoras

BNDES Banco Nacional do Desenvolvimento Econômico e Social

C\&T Ciência e Tecnologia

CAPES Coordenação de Aperfeiçoamento de Pessoal de Nível Superior

CAPRE Coordenação de Atividades de Processamento Eletrônico

CF/1988 Constituição da República Federativa do Brasil de 1988

CGEE Centro de Gestão e Estudos Estratégicos

CNAE Classificação Nacional de Atividades Econômicas

$\mathrm{CNPq} \quad$ Conselho Nacional de Desenvolvimento Científico e Tecnológico

$\mathrm{CPqD} \quad$ Centro de Pesquisa e Desenvolvimento da Telebrás

CT IT Coordenadoria de Transferência e Inovação Tecnológica

EMBRAPA Empresa Brasileira de Pesquisa Agrícola

FAPESP Fundação de Amparo à Pesquisa do Estado de São Paulo

FINEP Financiadora de Estudos e Projetos

FNDCT Fundo Nacional de Desenvolvimento Científico e Tecnológico

FUNTTEL Fundo para o Desenvolvimento Tecnológico das Telecomunicações

GATT General Agreement on Tarifs and Trade / Acordo Geral sobre Tarifas Aduaneiras e Comércio

IBGE Instituto Brasileiro de Geografia e Estatística

ICTs Instituições de Ciência e Tecnologia

IFES Instituições Federais de Ensino Superior

INMETRO Instituto Nacional de Metrologia e Qualidade

INOVA Agência de Inovação da Unicamp

INPI Instituto Nacional de Propriedade Industrial

ISIC International Standard Industrial Classification of all Economic Activities

LPI Lei de Propriedade Industrial - Lei ${ }^{\circ}$ 9.279/1996

MCTI Ministério da Ciência e Tecnologia e Inovação

MDIC Ministério Desenvolvimento Indústria e Comércio

MEC Ministério da Educação

NESTI Grupo de Especialistas Nacionais em Ciência e Tecnologia

NITs Núcleos de Inovação Tecnológica

NSF US National Science Foundation 
OCDE Organization for Economic Co-operation and Development / Organização de Cooperação e Desenvolvimento Econômico

OEEC Organization for European Economic Cooperation / Organização para a Cooperação Econômica Europeia

OMC Organização Mundial do Comércio

P\&D Pesquisa e Desenvolvimento

P\&D\&I Pesquisa, Desenvolvimento e Inovação

PBDCT Plano Básico de Desenvolvimento Científico e Tecnológico

PDP Política de Desenvolvimento Produtivo

PIB Produto Interno Bruto

PITCE Política Industrial, Tecnológica e de Comércio Exterior

PINTEC Pesquisa de Inovação Tecnológica

PLANIN Plano Nacional de Informática e Automação

PND Plano Nacional de Desenvolvimento

R\&D Research and Experimental Development

RFB Receita Federal do Brasil

RHAE Programa de Formação de Recursos Humanos em Áreas Estratégicas

SBPC Sociedade Brasileira para o Progresso da Ciência

SEI Secretaria Especial de Informática

SIBRATEC Sistema Brasileiro de Tecnologia

TI Tecnologia da informação

TICs Tecnologias da informação e da comunicação

TRIPS Trade Related Aspects of Intellectual Property Rights / Acordo sobre os Aspectos dos Direitos de Propriedade Intelectual Relacionados ao Comércio

TPP Inovações Tecnológicas em Produtos e Processos

UFMG Universidade Federal de Minas Gerais

UFRJ Universidade Federal do Rio de Janeiro

UNESCO Organização das Nações Unidas para a Educação, a Ciência e a Cultura

UNICAMP Universidade de Campinas

USP Universidade de São Paulo

WTO World Trade Organization 


\section{INTRODUÇÃO}

\subsection{Tema a ser desenvolvido e suas limitações}

Esta dissertação tem por escopo a análise dos reflexos da aplicação da Lei $\mathrm{n}^{\circ}$ 10.973/2004, Lei de Inovação, sobre o setor de tecnologias da informação e comunicação (TICs) no Brasil. A Lei de Inovação consolida medidas de incentivo à pesquisa e à inovação no ambiente produtivo brasileiro e produz efeitos desde o dia 2 de dezembro de 2004, data de sua promulgação.

O setor de TICs é composto por produtos, serviços e ou componentes que transmitem ou exibem a informação por meios eletrônicos. A definição de TICs baseia-se na Classificação Internacional da Indústria de todas as Atividades Econômicas (ISIC, do inglês, International Standard Industrial Classification of all Economic Activities - rev. 4). ${ }^{1}$ Os produtos de TICs são eletrônicos, mas nem todo produto eletrônico pode ser classificado como TICs, embora a convergência digital esteja reduzindo cada vez mais essa fronteira. $^{2}$ Atualmente, televisores, aparelhos de som, videogame, equipamentos de telecomunicações e outros eletrodomésticos convergem, com cada vez mais frequência, as suas funcionalidades a mecanismos de transmissão e exibição de informações.

O interesse do estudo do setor de TICs nesta dissertação partiu de duas observações: $(i)$ este setor representa um promissor celeiro de novas tecnologias e costuma receber forte estímulo de políticas de governo que priorizam desenvolvimento tecnológico como uma vantagem competitiva perante os países industrializados (e.g. Índia, atualmente, já considerada líder mundial na exportação de serviços de tecnologia da informação); $\mathrm{e}^{3}{ }^{4}$ (ii) as criações intelectuais incorporadas aos produtos e serviços de TICs são passíveis de proteção pela propriedade intelectual, notadamente, sob o formato de patentes e software.

\footnotetext{
${ }^{1}$ United Nations, International Standard Industrial Classification of all Economic Activities. Revision 4. New York, 2008. Disponível em: http://unstats.un.org/unsd/cr/registry/isic-4.asp. Acesso em set., 2012. ${ }^{2}$ SALLES FILHO, Sergio et al. Avaliação de impactos da Lei de Informática: uma análise da política industrial e de incentivo à inovação no setor de TICs brasileiro. Revista da Inovação. Campinas, SP, 11, n. esp., p. 191-218, julho 2012. p. 194.

${ }^{3} \mathrm{O}$ conceito de TICs reúne toda variedade de recursos tecnológicos que intermedeiam a comunicação e a troca de informações entre os indivíduos. Trata-se de um conceito mais amplo que abarca os elementos hardware, software, incluindo funções voz, dados e outros meios e formatos de comunicações no atendimento das demandas sociais.

${ }^{4}$ CRUZ, Carlos Henrique de Brito e CHAIMOVIC, Hernan. Relatório UNESCO sobre Ciência 2010. Capítulo 5 - Brasil, 2010, pp. 27.
} 
A análise proposta nesta dissertação sobre a promoção da inovação tecnológica no setor de TICs possui duas dimensões: as políticas públicas de estímulo ao desenvolvimento tecnológico brasileiro e a interferência da propriedade intelectual na promoção da inovação tecnológica.

Embora os efeitos de aplicação da Lei de Inovação sejam recentes, considera-se relevante o estudo dos reflexos dessa norma e dos demais enunciados que compõem o sistema nacional de inovação tecnológica no setor brasileiro de TICs. A inovação tecnológica tem preenchido a agenda de desenvolvimento de muitos países e, no Brasil, a necessidade de inovar está em foco e vem sendo perseguida, por intermédio de mudanças legislativas e pelo reposicionamento da indústria.

A Lei de Inovação dispõe sobre instrumentos jurídicos que buscam estimular parcerias entre membros do poder público e do setor privado e, de outro lado, regular as formas de aproveitamento da inovação no ambiente produtivo (e.g. licenciamento de uso de tecnologias, transferência de tecnologias, prestação de serviços de pesquisa e desenvolvimento, etc.). A análise desses instrumentos jurídicos será fundamental para o desenvolvimento desta dissertação, que parte da seguinte hipótese:

OS ACORDOS CELEBRADOS ENTRE AS INSTITUIÇÕES CIENTÍFICAS E TECNOLÓGICAS (ICTS) E O SETOR PRIVADO ESTÃO CONCENTRADOS NA TRANSFERÊNCIA DE TECNOLOGIA OU LICENCIAMENTO DE USO DE CRIAÇÃO DESENVOLVIDA PELA ICT, QUE LIMITADOS AO REGIME DO DIREITO PÚBICO APLICÁVEL ÀS CONTRATAÇÕeS PREVISTAS NA LEI DE INOVAÇÃO, não SÃO EFICAZES PARA A EFETIVA PROMOÇÃO DA INOVAÇ̃̃o TECNOLÓGICA NO SETOR DE TICS.

O setor de TICs brasileiro tem sido beneficiado por alterações legislativas que buscam privilegiar a produção de tecnologia nacional em detrimento de bens e serviços importados. Essas medidas, no entanto, ainda não colocam o setor de TICs brasileiro em posição competitiva frente aos concorrentes multinacionais. O processo inovador requer investimentos e uma estrutura favorável para sua execução, que pressupõe que a empresa que decidir inovar possua poder de mercado suficiente para assumir os custos e as incertezas da inovação. As empresas que formam o setor de TICs brasileiro, no entanto, oprimidas pela concorrência, não conseguem deslanchar na inovação e, na maioria das vezes são importadoras e imitadoras ${ }^{5}$ das inovações já desenvolvidas em outros países. ${ }^{6}$

\footnotetext{
${ }^{5}$ A caracterização da indústria brasileira como imitadora não significa, no entanto, que a imitação não pode levar à inovação. Especialmente para a indústria de software, a imitação é o primeiro passo para adquirirem o aprendizado necessário para desenvolverem suas próprias tecnologias. Na indústria automobilística, o caso da
} 
Considera-se que, em prol da promoção da inovação tecnológica no setor de TICs, os instrumentos jurídicos possam ser rearranjados e eventualmente, reestruturados. É importante ressaltar que a hipótese desta dissertação não se opõe aos objetivos e enunciados da Lei de Inovação, mas considera a existência de deficiências na articulação dos instrumentos jurídicos enunciados na lei referida em relação ao desenvolvimento pretendido pelo setor de TICs.

Não obstante o enfoque dado à Lei de Inovação, o estudo proposto contemplará a análise de outras fontes normativas relevantes para o setor TICs, incluindo as leis concernentes à proteção da propriedade intelectual - Lei $\mathrm{n}^{\circ}$ 9.279/1996 (Lei de Propriedade Industrial), Lei n 9.609/1998 (Lei de Software) - e outras leis que dispõem sobre benefícios a segmentos de mercado englobados em TICs, notadamente, Lei $\mathrm{n}^{\circ}$ 7.232/1984 (Lei de Informática), Lei n 11.196/2005 (Lei do Bem) e Lei n 12.349/2010, lei que altera dispositivos da Lei $n^{\circ} 8.666 / 1993$, dentre outras.

A inovação tecnológica depende de investimentos, no sentido de recursos financeiros e humanos. A difusão do conhecimento na forma de capacitação profissional de cidadãos dispostos e habilitados a entregar suas forças de trabalho à atividade inventiva é um dos gargalos para o desenvolvimento do sistema de inovação tecnológica no Brasil. Do ponto de vista do risco financeiro, os investimentos em atividades de Pesquisa e Desenvolvimento (P\&D) e Inovação (P\&D\&I) podem ser despendidos sem que se atinja o objetivo traçado.

$\mathrm{Na}$ análise econômica, os investimentos em P\&D são classificados como custos irrecuperáveis, sunk costs, ou irreversíveis, que são valores despendidos pelo empresário em infraestrutura, recursos humanos etc. que não podem ser diretamente recuperados. Os

Toyota é emblemático, pois esta empresa deu início a suas atividades, em 1930, com imitação dos sistemas produtivos da Ford. Já na década de 1960, a empresa japonesa, contudo, consagrou o seu eficiente sistema de produção de automóveis, conhecido por "lean manufacturing" (gestão focada na redução de desperdícios na produção, resultando em aumento da produção e diminuição de custos e tempo de produção). Ver:

GALHARDI, Antonio Cesar e ZACCARELLI, Sérgio Baptista. Inovação e Imitação Tecnológica como Estratégia Competitiva. Revista Brasileira de Gestão de Negócios, p. 23-29, abril, vol. 7, n. 017, 2005. p. 24.

${ }^{6}$ As recentes alterações na Lei n. ${ }^{\text {0 }}$ 8.666/1993 por intermédio da Lei n. ${ }^{\circ}$ 12.439/2011, resultado da conversão da MPV n. ${ }^{\circ} 495 / 2010$, demonstram a intenção do Estado em promover seu poder de compra da inovação tecnológica nacional. A equiparação do "Tablet" ao computador para fins de benefícios físcais concedidos pela Lei n. ${ }^{\circ}$ 11.196/1995, Lei do Bem, é outro exemplo de impulsão ao setor de TICs no Brasil. 
custos e incertezas com a inovação são fatores que inibem a entrada de novos concorrentes no mercado. ${ }^{7}$

Nesse contexto de incertezas e recuos frente aos riscos da inovação, o papel do Estado no processo inovador é muito relevante (e.g. financiamentos públicos, por meio de poder de compra, investimentos em P\&D, subvenção e outros incentivos). Há, na atualidade, previsão legal de arranjos jurídicos, pelos quais o Estado compartilha riscos do processo da inovação tecnológica com as empresas (“Estado Tomador de Risco”). ${ }^{8}$ No contexto nacional de uma indústria pouco inovadora, as subvenções e financiamentos públicos são essenciais como ponto de partida para a inovação tecnológica. Entretanto, concentrar no longo prazo os investimentos em inovação tecnológica somente nos recursos públicos, parece não ser a estratégia adequada para estimular o desenvolvimento da indústria brasileira.

A propriedade intelectual é um elemento de mitigação dos riscos e incertezas inerentes às atividades de $\mathrm{P} \& D \& \mathrm{I}$. O investidor em inovação deseja assegurar sua propriedade sobre a criação, caso passível de proteção pelo sistema de propriedade intelectual, para explorá-la sem limitações nos diversos territórios em que atue. Dessa forma, a propriedade intelectual pode simbolizar a certeza da exploração e a expectativa de retornos (e.g. royalties) dos investimentos aplicados nas atividades de P\&D\&I. Nesta dissertação, a proteção da propriedade intelectual sobre o setor de TICs, especialmente com relação ao setor de software, será analisada.

\subsection{Justificativa da escolha e importância do tema}

A “endogeneização do progresso tecnológico" é um grande desafio para países em desenvolvimento. O Brasil é um país em desenvolvimento, de acordo com a classificação do Banco Mundial baseada na renda per capita das economias de 214 países considerados na análise desse Banco ${ }^{9}$. Tradicionalmente, o desenvolvimento tecnológico desses países em desenvolvimento foi solapado por decisões políticas que buscavam contornar crises econômicas e combater problemas sociais. A preocupação com situações de miséria,

\footnotetext{
${ }^{7}$ PINDICK, Robert S. e RUBINFELD, Daniel L. Microeconomia. 7 a Ed., São Paulo: Pearson Education do Brasil, 2010, pp. 194.

${ }^{8}$ Adota-se no presente estudo a expressão "Estado Tomador de Risco" utilizada por MATTOS, 2009, p. 103 (op.cit., nota infra 160).

${ }^{9}$ The World Bank. Classificação dos Países (Country and Lending Groups). Disponível em: http://data.worldbank.org/about/country-classifications/country-and-lending-groups. Acesso em dez., 2012.
} 
instabilidade política e colapsos econômicos são fatores que, na maioria dos casos, inviabilizam o direcionamento de políticas para o desenvolvimento tecnológico de um país.

A promoção da inovação tecnológica no Brasil está embasada nos arts. 218 e 219 no Capítulo IV - Da Ciência e Tecnologia da Constituição Federal de 1988 (CF/1988) e nos princípios do Acordo sobre Aspectos dos Direitos de Propriedade Intelectual relacionados ao Comércio (TRIPS), acordo que o Brasil e demais países membros da Organização Mundial do Comércio (OMC) são signatários desde $1994 .{ }^{10}$ O lapso temporal entre a CF/1988 e o marco da inovação tecnológica com a Lei 10.973/2004 demonstra a dificuldade brasileira em dispor sobre os incentivos à inovação tecnológica.

Diante da conscientização de que a inovação tecnológica é um diferencial competitivo para o crescimento econômico brasileiro. O estudo proposto nesta dissertação tende a ser bastante instigante ${ }^{11}$. As circunstâncias atuais de fortalecimento da economia brasileira e as expectativas de maior competitividade da indústria nacional face ao mercado global são fatores favoráveis ao desenvolvimento tecnológico de setores de infraestrutura estratégicos, como o setor de TICs. ${ }^{12}$

Antes da promulgação da Lei de Inovação, vigoravam normas esparsas e regionalizadas que procuravam estabelecer parâmetros entre a pesquisa científica básica,

\footnotetext{
${ }^{10}$ A sigla TRIPS abrevia a expressão, em inglês, Agreement on Trade-Related Aspects of Intellectual Property Rights. De acordo com os arts. $7^{\circ}$ e $8^{\circ}$ do TRIPS "a proteção e aplicação de normas de proteção dos direitos de propriedade intelectual devem contribuir para a promoção da inovação tecnológica e para a transferência e difusão de tecnologia, em benefício mútuo de produtores e usuários de conhecimento tecnológico e de uma forma conducente ao bem-estar econômico e a um equilíbrio entre direitos e obrigações". Os comentários ao art. $7^{\circ}$ na publicação da UNCTAD-ICTSD. Resource Book on TRIPS and Development. 2005 ressaltam a preocupação dos países em desenvolvimento, membros do TRIPS, na interpretação dos arts. $7^{\circ}$ e $8^{\circ}$ sob a alegação de que somente os objetivos relacionados à proteção dos bens tecnológicos dos países desenvolvidos têm sido observados.

${ }^{11}$ A articulação atual de esforços do Governo Federal, por intermédio do Ministério de Ciência Tecnologia e Inovação (MCTI), do Ministério do Desenvolvimento, Indústria e Comércio Exterior (MDIC), FINEP, BNDES, CNPq e outras agências de fomento à pesquisa é bastante intensa, sendo o setor de TICs priorizado nas políticas de incentivo à inovação tecnológica. Exemplo disso é o Programa TI Maior, lançado pelo MCTI em 20 de agosto de 2012, com a finalidade de fomentar a indústria de software e serviços na área de tecnologia da informação. Inicialmente, para o período de 2012-2015, o TI Maior terá investimentos na ordem de R \$500 milhões para atingir os objetivos traçados pelo MCTI. Disponível em: http://www.mct.gov.br/index.php/content/view/341556.html. Acesso em nov., 2012.

${ }^{12}$ De acordo com relatório da Financiadora de Estudos e Projetos (FINEP). (BRANDÃO, Vladmir, GONÇALVES, Ada Cristina et al. Brasil inovador: o desafio empreendedor: 40 histórias de sucesso de empresas que investem em inovação. CARLOS GANEM e ELIANE MENEZES DO SANTOS (coord.), 2006, pp. 27: "Há setores da economia brasileira em que a inovação é amplamente reconhecida, como o de petróleo e o de telecomunicações. O investimento público esteve na gênese desse avanço. As telecomunicações são um exemplo de como o Estado foi importante para a consolidação de uma capacidade inovadora de ponta, que é característica do setor até os dias atuais. Os serviços e pesquisas na área começaram a ser realizados por empresas públicas estaduais e federais, que posteriormente foram reunidas no chamado Sistema Telebrás, criado na década de 70.”
} 
priorizada pelo Estado brasileiro, nos termos da Constituição Federal, o desenvolvimento científico e a capacitação tecnológica. A pesquisa científica básica limita-se ao âmbito acadêmico e não visa à aplicação industrial do resultado obtido com as atividades de pesquisa e desenvolvimento. As atividades voltadas à inovação tecnológica, por outro lado, perseguem o aproveitamento da criação no mercado.

A Lei de Inovação foi importante para uniformizar definições e regular as formas de relacionamento entre as Universidades, centros de pesquisas, denominadas, em conjunto, Instituições Científicas Tecnológicas (ICTs) e as empresas ${ }^{13}$. Além disso, a Lei de Inovação dispõe sobre meios de financiamento das atividades de P\&D\&I, notadamente com aporte de recursos públicos de fundos setoriais (por exemplo, FUNTTEL) e a intermediação de agências de fomento (por exemplo, FINEP, BNDES, etc.). Nesta dissertação, essa Lei será considerada como o marco regulatório da inovação tecnológica. A análise desse marco, no entanto, dependerá do estudo das normas e instituições existentes antes de 2005 que tinham por escopo o desenvolvimento tecnológico brasileiro.

A escolha do setor de TICs para análise nesta dissertação foi motivada pelas transformações atravessadas pelo setor nas últimas décadas, desde as políticas de fortalecimento da indústria nacional de informática até a abertura do mercado à competição internacional, durante a década de $1990 .{ }^{14}{ }^{15}$

Do ponto de vista da proteção da propriedade intelectual, a discussão estará concentrada na indústria de software.

\footnotetext{
${ }^{13}$ Ver a definição de ICT na descrição dos “atores" da inovação tecnológica na seção Error! Reference source not found. do Capítulo 3.

${ }^{14}$ Em relatório publicado pela Secretaria de Política Informática - SEPIN, do Ministério da Ciência e Tecnologia (MCT). Tecnologia da Informação: A Legislação Brasileira, 2010. Disponível em <http://www.mct.gov.br/index.php/content/view/32784.html >, acesso em (11/2010), estão catalogadas as normas aplicáveis ao setor de Tecnologia da Informação (TI), ressalte-se que as leis referentes às "Comunicações" não são parte deste estudo.

${ }^{15}$ As recentes diretrizes definidas no Dec. 7.175 de 12/05/2010 ressuscitam a TELEBRÁS para que esta assuma prestação e gerencie o provimento da "infraestrutura e redes de suporte a serviços de telecomunicações prestados por empresas privadas" (Art. $4^{\circ}$, III). Trata-se de mais uma alteração no setor de TICs que tem como objetivos principais: "acelerar o desenvolvimento econômico e social"; e "aumentar a autonomia tecnológica e a competitividade [das empresas] brasileiras.” (Art. 3º, II e VIII).
} 


\subsection{Objetivos}

Esta dissertação tem por escopo :

(i) analisar o arcabouço normativo do Sistema Nacional da Inovação Tecnológica;

(ii) analisar os programas governamentais de estímulo ao desenvolvimento tecnológico do setor de informática brasileiro;

(iii) examinar a participação da proteção da propriedade intelectual do software na promoção da inovação tecnológica;

(iv) investigar as deficiências na articulação dos interesses de ICT e setor privado, conforme os instrumentos jurídicos previstos na Lei de Inovação e;

(v) apresentar possíveis proposições para contornar os problemas identificados.

\subsection{Metodologia a ser utilizada}

A análise deste estudo é jurídica e, ainda que o tema proposto seja interdisciplinar, eventuais abordagens não-jurídicas serão consideradas complementares e elucidativas. $\mathrm{O}$ tema proposto já vem sendo discutido pela economia e administração e possui forte influência de teorias de desenvolvimento econômico. Durante a investigação realizada verificou-se que, embora o tema da inovação tecnológica esteja no foco nas agendas de desenvolvimento de diversos países, ainda é um assunto pouco explorado nas pesquisas acadêmicas de direito. Por tal razão, o estudo da literatura de outras áreas do conhecimento é inevitável para realização deste trabalho e acredita-se que essa interdisciplinaridade só tem a incrementar a análise proposta.

A dissertação será dividida em quatro grandes blocos, que consistirão: (i) na análise do conceito de inovação e da estrutura do sistema brasileiro da inovação tecnológica; (ii) estudo sobre o setor de TICs com ênfase na indústria brasileira de software; (iii) análise dos modelos contratuais enunciados na Lei de Inovação para viabilizar a promoção da inovação tecnológica por intermédio das ICTs; e por fim, (iv) a indicação de possíveis soluções às hipotéticas deficiências verificadas na promoção da inovação tecnológica no setor de TICs. 
Considerando que a Lei de Inovação produz efeitos há poucos anos no sistema jurídico brasileiro, eventuais controvérsias decorrentes da aplicação da Lei de Inovação não chegaram aos tribunais brasileiros até a data de conclusão desta dissertação. Portanto, a análise jurisprudencial não é escopo desta dissertação.

A análise da estrutura do sistema brasileiro de inovação tecnológica e o arcabouço legislativo do setor de TICs constituem a primeira parte da pesquisa (Análise Normativa). Em relação ao setor de TICs, a análise será dividida em duas vertentes, sendo a primeira relativa às políticas de desenvolvimento tecnológico aplicadas ao setor brasileiro de TICs e a segunda voltada à proteção conferida pela propriedade intelectual ao software. Os instrumentos jurídicos enunciados pela Lei de Inovação e outros arranjos jurídicos adotados para promover a inovação no setor de TICs serão investigados durante o desenvolvimento desta pesquisa (Análise Contratual).

Os aspectos relacionados aos incentivos fiscais para que as empresas invistam em P\&D e a análise, sob a perspectiva tributária, do acesso a linhas de financiamento e ou à subvenção disponibilizadas pelo poder público ao setor privado não é escopo desta dissertação. Não obstante, para a análise dos arranjos jurídicos utilizados para promoção da inovação tecnológica, é inevitável que se aborde, ainda que de modo superficial, os benefícios fiscais criados em vista do mesmo propósito.

A relação jurídica para promoção da inovação tecnológica pode ser estabelecida nos âmbitos interno e externo à empresa. Há empresas que têm as atividades de $\mathrm{P} \& \mathrm{D}$ como objeto social ou mesmo aquelas que investem em inovação por meio de seus departamentos internos de P\&D. Por outro lado, há empresas que procuram produtos e serviços inovadores junto a agentes externos, fora de sua estrutura, por exemplo, por meio de parcerias com ICTs para realização de atividades conjuntas de pesquisa científica e tecnológica, licenciamento de uso ou transferência de tecnologias e prestação de serviços por profissionais capacitados ao desenvolvimento de pesquisa tecnológica. Nas duas situações, identifica-se a empresa como promotora da inovação tecnológica e responsável pelos investimentos; seja por meio seus próprios recursos ou via financiamento, subvenção estatal ou outras fontes de recursos disponíveis.

Os instrumentos jurídicos que moldam e estruturam as atividades de $\mathrm{P} \& \mathrm{D}$ interno nas empresas são, em sua maioria, sigilosos e, portanto, inacessíveis para análise proposta nesta dissertação. Os instrumentos jurídicos propostos por ICTs, por meio de seus núcleos de inovação tecnológica (NITs), que visam licenciar o uso de tecnologias, firmar acordos 
de cooperação científica e tecnológica, dentre outras formas contratuais enunciadas na Lei de Inovação, encontram-se, em parte, disponíveis nas páginas eletrônicas (sites) dessas instituições e serão analisados nesta dissertação ${ }^{16}$. A análise aprofundada dos instrumentos contratuais utilizados para promoção da inovação tecnológica é fundamental para comprovar a hipótese deste trabalho e para que sejam indicados os incentivos mais apropriados para a promoção da inovação em TICs.

Adicionalmente, a análise contratual será complementada com os resultados da Pesquisa de Inovação Tecnológica (PINTEC) realizada pelo Instituto Brasileiro de Geografia e Estatística ${ }^{17}$, em suas edições de 2005 e 2008, e com as informações obtidas junto ao Instituto Nacional de Propriedade Industrial (INPI), representantes da indústria de software, com os agentes do sistema brasileiro de inovação tecnológica vinculados ao poder público (e.g. Ministérios, Agências de Fomento, etc.) e membros do setor privado (e.g. agências de inovação, associações e fundações de direito privado, etc.). Com a análise dessas informações pretende-se identificar os resultados da inovação tecnológica no setor de TICs.

Os dados da PINTEC 2008 adotam a Classificação Nacional de Atividades Econômicas - CNAE 2.0 ${ }^{18}$. De acordo com essa Classificação, as atividades de telecomunicações e serviços de tecnologia da informação encontram-se nas divisões 61 e 62 da seção J do CNAE 2.0 e foram objeto da análise da PINTEC 2008. Na PINTEC 2008, as atividades de edição e gravação e edição de música, telecomunicações, atividades dos serviços de tecnologia da informação, incluindo, mas sem se limitar ao desenvolvimento e licenciamento de programas de computador, tratamento de dados, hospedagem na internet e outras atividades relacionadas a pesquisa e desenvolvimento são analisadas em conjunto sob o título de serviços selecionados. ${ }^{19}$

A PINTEC 2008 analisou as informações do período de 2006 a 2008, sendo que nas edições anteriores de 2000 e 2005 foram examinadas as informações relativas à inovação nos triênios de 1998 a 2000 e 2003 a 2005, respectivamente. Os resultados das PINTEC

\footnotetext{
${ }^{16}$ Ver, nesse sentido, a análise dos instrumentos jurídicos da Lei de Inovação na seção Error! Reference source not found. do Capítulo 3.

${ }^{17}$ Ver a análise da promoção da inovação tecnológica na empresa na seção Error! Reference source not found. do Capítulo 3. Nesta dissertação, a análise da PINTEC 2008 foi priorizada, tendo em vista que o período pesquisado pelo IBGE (2006 a 2008) coincide com os anos posteriores da Lei de Inovação.

${ }^{18}$ A análise da CNAE e do setor de TICs foi realizada no Capítulo 2, mais especificamente na seção Error! Reference source not found..

${ }^{19}$ IBGE. Pesquisa de Inovação Tecnológica - PINTEC 2008, 2010, pp. 17. Disponível em <http://www.ibge.gov.br/home/estatistica/economia/stic/default.shtm>, acesso em jun., 2011.
} 
entre 2005 e 2008 retratam os períodos anteriores e já posteriores aos efeitos da Lei de Inovação, em vigor desde a data de sua publicação, em 2 de dezembro de 2004. A análise dos resultados dessas pesquisas do IBGE, associada ao exame dos instrumentos jurídicos adotados pelos atores da inovação tecnológica, após a Lei de Inovação, são fundamentais para a análise proposta nesta dissertação.

\section{Análise Normativa}

O estudo da promoção da inovação tecnológica pressupõe a análise das normas aplicáveis. Ainda que a promoção da inovação tecnológica componha a agenda atual do Brasil e de outros países na corrida pelo desenvolvimento tecnológico, antes da Lei de Inovação já vigoravam normas esparsas e organizações governamentais e não governamentais que tinham por missão o desenvolvimento tecnológico nacional (e.g. Conselho Nacional de Desenvolvimento Científico e Tecnológico - CNPq, Financiadora de Estudos e Projetos - FINEP).

Potencializado pela existência dessa estrutura organizacional e normativa prévia, o sistema brasileiro de inovação tecnológica é formado por um emaranhado de normas e poderes concentrados em diversos Ministérios, Agências e outras organizações. A estrutura complexa do Sistema Nacional da Inovação Tecnológica será graficamente representada nesta dissertação ${ }^{20}$.

O Ministério de Ciência e Tecnologia e Inovação - MCTI sedia o Portal da Inovação e aparece como forte impulsionador da inovação tecnológica em busca de alianças entre setor produtivo e as atividades de P\&D\&I. O envolvimento direto do MCTI, em detrimento do Ministério do Desenvolvimento, Indústria e Comércio - MDIC é criticado, afinal, a inovação visa o aproveitamento no mercado e os representantes da indústria e comércio deveriam estar comprometidos e diretamente envolvidos com esse propósito. Atualmente, no entanto, essa barreira vem sendo superada e os Ministérios têm atuado em conjunto em iniciativas de promoção da inovação tecnológica nas empresas ${ }^{21}$.

\footnotetext{
${ }^{20}$ Ver Error! Reference source not found. no Capítulo 1.

${ }^{21}$ A Secretaria de Inovação do Ministério de Desenvolvimento, Indústria e Comércio Exterior - MDIC em parceria com a Secretaria de Política de Informática do MCTI, Comitê Executivo e o Conselho de Competitividade relacionados às Tecnologias da Informação e Comunicação (TIC) e ao Complexo Eletroeletrônico do Plano Brasil Maior são responsáveis pela elaboração de políticas públicas e ações governamentais referentes ao tema da promoção da inovação tecnológica no setor de TICs. Ver MDIC. TIC
} 
De outro lado, o Ministério da Educação - MEC, tendo em vista o déficit educacional brasileiro, passou a ser protagonista na promoção da inovação tecnológica com intuito da capacitação nacional no longo prazo, por meio de investimentos nos níveis de educação superior, em busca de profissionais qualificados para atender as demandas do mercado e no nível fundamental. Assim como mencionado na parceria do MDIC e MCTI, o MEC também está envolvido em programas de qualificação de recursos humanos (e.g. no âmbito do Plano Brasil Maior em associação ao MDIC) $)^{22}$.

Além da Lei $\mathrm{n}^{\mathrm{o}}$ 10.973/2004, diversas leis estaduais foram promulgadas visando à instituição de benefícios para estimular a inovação tecnológica em seus territórios que, em conjunto com a Lei de Inovação, consolidam o sistema nacional de inovação. As leis estaduais dispõem sobre a criação de núcleos de inovação tecnológica nos Estados e sobre linhas de financiamento e subvenções disponíveis às empresas em cada Estado.

As normas de promoção da inovação tecnológica no setor de TICs relacionam-se aos incentivos do Estado brasileiro ao setor de informática e ao processo produtivo básico. As leis aplicáveis à proteção da propriedade intelectual e à destinação de incentivos aos investidores da inovação tecnológica serão parte da Análise Normativa realizada nesta dissertação, que contemplará três principais conjuntos de normas, indicadas abaixo de forma não exaustiva:

(a) Sistema brasileiro da inovação tecnológica:

- Lei n. ${ }^{\circ}$ 10.973, de 2 de dezembro de 2004, Lei de Inovação;

- Decreto $\mathrm{n}^{\mathrm{o}}$ 5.563, de 11 de outubro de 2005, que regulamenta a Lei de Inovação;

- Lei no 11.196, de 21 de novembro de 2005, Lei do Bem;

- Decreto ${ }^{\circ}$ 5.798, de 7 de junho de 2006, que regulamenta a Lei do Bem;

- Lei no. 11.487, de 15 de junho de 2007, "Lei do MEC de Inovação" ou "Lei Rouanet da Inovação";

- Decreto $\mathrm{n}^{\circ}$ 6.260, de 20 de novembro de 2007, que regulamenta a Lei n. $^{\circ}$ 11.487/2007;

- Lei $n^{\circ} 12.349$, de 15 de dezembro de 2010, que altera as Leis $n^{\circ} 8.666 / 1993$, 8.958/1994 e 10.973/2004; e

no Plano Brasil Maior. Disponível em http://www.desenvolvimento.gov.br/sitio/interna/interna.php?area=3\&menu=2527 . Acesso dez., 2012.

22 MDIC. Governo vai qualificar mão-de-obra em setores do Plano Brasil Maior. Disponível em:

http://www.desenvolvimento.gov.br/sitio/interna/noticia.php?area=3\&noticia=12031. Acesso em dez., 2012. 
- Leis Estaduais: Lei Complementar no 1.049/2008 de São Paulo e Decreto n 53.963/2009, Lei ${ }^{\circ} 17.349 / 2008$ de Minas Gerais, Lei ${ }^{\circ} 1.913 / 2008$ do Rio de Janeiro, dentre outras.

(b) Políticas de desenvolvimento industrial do setor de informática:

- Lei $n^{\circ}$ 7.232, de 29 de outubro de 1984, que dispõe sobre a Política Nacional de Informática;

- Lei no 8.248, de 23 de outubro de 1991, que dispõe sobre a capacitação e competitividade do setor de informática e automação;

- Portaria MCT n 950, de 12 de dezembro de 2006, que caracteriza bens ou produtos com tecnologia desenvolvida no país;

- Lei $n^{\circ} 10.176$, de 11 de janeiro de 2001, que dispõe sobre a capacitação e competitividade do setor de tecnologia da informação; e

- Normas que compõem o Sistema Brasileiro de Tecnologia - SIBRATEC, em especial o Decreto $\mathrm{n}^{\mathrm{o}} 6259$, de 20 de novembro de 2007, que institui o SIBRATEC.

(c) Propriedade Intelectual:

- Decreto $\mathrm{n}^{\mathrm{o}} 1.355$, de 30 de dezembro de 1994, promulga a ata final que incorpora os resultados da Rodada do Uruguai no Acordo TRIPS;

- Lei n 7.646, de 18 de dezembro de 1987 (revogada pela Lei de Software);

- Lei no 9.279, de 14 de maio de 1996, Lei de Propriedade Industrial; e

- Lei n ${ }^{\circ}$ 9.609, de 19 de fevereiro de 1998, Lei de Software.

\section{Análise Contratual}

Com base nas disposições da Lei de Inovação Tecnológica, identificam-se três principais modelos contratuais que aproximam as ICTs e os núcleos de inovação tecnológica (NITs) de agentes externos, tanto do setor público como do privado. Nos termos do art. $6^{\circ}$ da Lei de Inovação e Decreto n ${ }^{\circ}$ 5.563/2005, há previsão dos contratos de transferência de tecnologia e licenciamento para outorga de direito de uso de criação desenvolvida pela ICT. O art. $9^{\circ}$ da Lei de Inovação dispõe sobre outro modelo contratual de parceria para realização de atividades conjuntas de pesquisa científica e tecnológica e desenvolvimento de tecnologia, produto ou processo, com instituições públicas e privadas. Além de disposições relativas à prestação dos serviços por profissionais da ICT no $\operatorname{art.} 8^{\circ}$, a 
Lei de Inovação prevê no art. 11 a cessão gratuita dos direitos sobre a criação pela ICT ao inventor, mediante manifestação expressa do órgão máximo da $\mathrm{ICT}^{23}$.

Diante dos modelos contratuais previstos na Lei de Inovação, a documentação jurídica, que compõe o acervo utilizado pelos NITs das ICTs, notadamente, as agências de inovação da Universidade de São Paulo (USP), Universidade de Campinas (UNICAMP), Universidade Federal do Rio de Janeiro (UFRJ) e da Universidade Federal de Minas Gerais (UFMG) será analisada nesta dissertação. Portanto, a Análise Contratual será concentrada nos indicadores de inovação tecnológica baseada nos contratos celebrados por ICTs vinculadas aos NITs referidos.

O objetivo da análise desses instrumentos jurídicos é verificar a predominância dos contratos de licenciamento de uso e transferência de tecnologia entre os instrumentos jurídicos celebrados por ICTs e empresas, nos termos da Lei de Inovação. Com isso, pretende-se identificar as eventuais deficiências desses acordos na promoção da inovação no setor de TICs, com ênfase no setor de software.

A partir da análise das informações disponíveis dos NITs referentes à intermediação e celebração de licenciamentos e transferências de uso de tecnologia e acordos de cooperação científico-tecnológicos celebrados por ICTs e empresas, buscar-se-á comprovar a hipótese desta dissertação de que o licenciamento de uso de tecnologia é o instrumento jurídico priorizado nos arranjos entre ICTs e empresas. Dessa forma, a análise dos indicadores dos NITs deve confirmar a tendência de que acordos de cooperação técnico-científicos que regem efetivas parcerias entre ICTs e empresas são menos frequentes, em comparação aos contratos de licenciamento de uso. O desentrosamento entre as ICTs e o ambiente produtivo será examinado em contraposição aos indicadores do PINTEC 2008 que apresentam os resultados da inovação tecnológica na indústria.

A análise dos contratos que formalizam os negócios e parcerias entre ICTs e membros dos setores público e privado considerará o papel da propriedade intelectual na promoção da inovação tecnológica. As criações intelectuais incorporadas aos produtos, serviços e componentes do setor de TICs podem ser protegidas por institutos da propriedade industrial (por exemplo, patentes, marcas, desenhos industriais), bem como na forma de software e até do segredo de negócio. Esta dissertação tem por escopo a análise da proteção da propriedade intelectual ao software.

\footnotetext{
${ }^{23}$ Ver a análise dos instrumentos jurídicos da Lei de Inovação na seçãoError! Reference source not found. do Capítulo 3.
} 
A apropriação da propriedade intelectual por meio dos acordos firmados entre ICTs e empresas será investigada, considerando as disposições da Lei de Inovação e sob a perspectiva do empresário que pretende explorar a inovação no mercado.

A análise dos contratos celebrados entre ICTs e membros do setor produtivo baseiase na definição da Lei de Inovação de ICT como órgão ou entidade da administração pública. Dessa forma, a maioria dos contratos firmados com as ICTs é regida pelas normas do direito público, segundo os ditames da Lei de Inovação e da Lei n. ${ }^{\circ}$ 8.666/1993.

A interpretação de contratos administrativos é bastante distinta da análise de contratos regidos pelo direito privado, pois, em certa medida, determinados princípios caracterizadores (e.g. princípio da igualdade entre as partes, autonomia da vontade e força obrigatória das convenções) dos contratos em geral não são aplicáveis aos contratos firmados com a administração pública. Basicamente, em relação às características dos contratos administrativos em contraposição aos contratos em geral destacam-se a finalidade pública, o caráter de adesão e a obediência à forma prescrita em lei. ${ }^{24}$

A publicação de edital para outorga de direito exclusivo de uso e exploração de criação desenvolvida pela ICT, nos termos do art. $6^{\circ}$ da Lei de Inovação, é exemplo de obrigação imposta pelo direito administrativo. A publicação de edital é uma alternativa ao dever de licitar da Lei n. ${ }^{\circ}$ 8.666/1993 e apresenta-se como um mecanismo menos burocrático para uso e exploração de novas tecnologias. Do ponto de vista dos membros do setor produtivo, contudo, a publicação do edital é vista como um obstáculo para manutenção do sigilo e para estratégias competitivas das empresas.

A promoção da inovação tecnológica, no entanto, não deve depender exclusivamente de contratos celebrados com a administração pública. O Estado deve incentivar e promover a inovação tecnológica, conforme previsto no art. 218 da CF/1988, mas é importante que as empresas também assumam os riscos decorrentes do processo inovador. Caso contrário, os níveis de inovação tecnológica continuarão pouco significantes, mesmo havendo disponibilidade de dinheiro público para investimentos em inovação.

Os acordos de cooperação técnico-científico, previstos no art. $9^{\circ}$ da Lei de Inovação, representam um modelo alternativo de parceria que congrega investimentos de

${ }^{24}$ DI PIETRO, Maria Sylvia Zanella, Direito Administrativo. $18^{a}$ Ed., São Paulo: Atlas, 2005, pp. 241 e 251. Ver análise das dificuldades inerentes à contratação com a administração pública na seção Error!

Reference source not found. do Capítulo 3. 
ICTs e empresas. Em princípio, esse arranjo jurídico tende a ser mais apropriado para a promoção da inovação tecnológica no setor de TICs.

A análise jurídica proposta nesta dissertação pretende ser útil à identificação das deficiências na articulação dos arranjos jurídicos para promoção da inovação tecnológica no setor de TICs. Além disso, a conclusão deste trabalho busca contribuir com soluções para as deficiências identificadas na relação do ambiente de pesquisa científica básica ou tecnológica (ICTs) e os interesses da indústria nacional, sob o pressuposto de a inovação tecnológica é vislumbrada por representantes do governo e do setor privado como o diferencial competitivo necessário para o crescimento econômico brasileiro. 


\section{CONCLUSÃO}

O objetivo desta dissertação sintetiza-se na hipótese de que os instrumentos jurídicos utilizados para a articulação de interesses dos representantes das ICTs e empresários não são eficazes para a promoção da inovação tecnológica no setor de TICs, notadamente, para a indústria software. A análise dos resultados dos relatórios do MCTI sobre as ICTs e dos NITs selecionados (vinculados às universidades públicas UNICAMP, USP, UFMG e UFRJ) comprovou a tendência de que os acordos celebrados por membros do setor produtivo e as universidades públicas concentram-se no objeto de transferência de tecnologia ou licenciamento do uso de criação já desenvolvida pela ICT, em conformidade com o art. $6^{\circ}$ da Lei de Inovação.

As condicionantes impostas pela Lei de Inovação ao acordo de transferência de tecnologia ou licenciamento de uso de criação desenvolvida pela ICT são inconvenientes para o setor de software. O desenvolvimento do software é caracterizado pelos efeitos de rede, sendo essencialmente muito caro produzir um programa de computador e muito barato reproduzi-lo. Adicionalmente, a proteção da propriedade intelectual ao software é caracterizada pela coexistência de regimes. Assim, ao programa de computador e processos por ele executados são conferidos a proteção dos direitos autorais, patentes, desenho industrial e as restrições ao segredo de negócio e indústria.

De acordo com o art. $6^{\circ}$ da Lei de Inovação, os contratos de transferência de tecnologia ou licenciamento de uso de criação desenvolvida pela ICT podem ser celebrados com ou sem obrigações de exclusividade. Caso opte-se por um regime de exclusividade, a ICT deve publicar edital contendo a descrição "sucinta e clara" do objeto do licenciamento, condições para contratação de possíveis interessados, critérios técnicos para qualificação da contratação mais vantajosa, prazos e condições para comercialização da criação, objeto do licenciamento.

A condição de exclusividade por si não é um obstáculo que inviabiliza a negociação de contratos de licenciamento de uso de programa de computador. De fato, a exclusividade no licenciamento de uso de programa de computador é uma opção pouco frequente, tanto no âmbito das licenças de software proprietário como, obviamente, no open source. A cláusula de exclusividade nos contratos de licenciamento pode ser aplicada de forma absoluta, no intuito de impedir que o licenciado utilize o programa de computador no 
mercado pertinente; ou relativa, no sentido de comprometer o licenciado a não sublicenciar o uso do programa de computador a terceiros, resguardado o uso próprio do licenciado. No caso da contratação baseada no art. $6^{\circ}$ da Lei de Inovação, a exclusividade visa tornar o objeto do contrato, isto é, a tecnologia ou uso da criação, indisponível a terceiros, de forma absoluta e relativa ${ }^{25}$.

Por um lado, a proteção autoral da propriedade intelectual ao software assegura ao titular, independentemente de registro, formas de proteção de seus direitos no uso e comercialização dos programas de computador. De outro lado, a indústria de software também utiliza proteção à confidencialidade como forma de impedir que terceiros não autorizados se apropriem das informações sigilosas concernentes ao programa de computador e documentação que o acompanha. Com base nesses regimes protetivos, o emprego da exclusividade no licenciamento de uso do software se torna bastante limitado.

Entretanto, a publicidade dada por edital, como condição para o regime de exclusividade ao contrato enunciado no art. $6^{\circ}$ da Lei de Inovação, é uma condição rejeitada pelo setor de software. O segredo depende da adoção de medidas mínimas de proteção pela parte divulgadora, caso contrário a informação é considerada como parte do domínio público. Portanto, a publicação de edital pela ICT com informações sobre a criação se torna o problema mais crítico na contratação de transferência de tecnologia ou licenciamento de uso nos termos da Lei de Inovação.

Ressalte-se que a publicação do edital não só implica revelação de informações sigilosas sobre o software, desenvolvido pela ICT, mas também pode prejudicar a competitividade do empresário disposto a inovar ao divulgar, prematuramente, aos seus concorrentes informações estratégicas sobre o objeto do acordo a ser firmado com a ICT. Considera-se que para o setor de software essa consequência no âmbito concorrencial é ainda mais relevante, uma vez que, com a alta velocidade de desenvolvimento de programas de computador, o concorrente pode facilmente obter licença de uso de software com funcionalidades semelhantes junto a outros fornecedores de tecnologia, sem ficar vinculado às limitações da Lei de Inovação. Nestas circunstâncias, o concorrente que contratar, em caráter de sigilo, o uso de tecnologia junto a fornecedores no mercado obteria notável vantagem competitiva em relação ao empresário disposto a licenciar o uso de criação da ICT.

${ }^{25}$ Op. cit, BARBOSA, 2011, p. 73. 
As condições do art. $6^{\circ}$ da Lei de Inovação decorrem da aplicação do regime do direito público às contratações celebradas por ICT e terceiros. A ICT, de acordo com a referida Lei, é órgão ou entidade da administração pública que tem por escopo executar atividades de pesquisa básica ou aplicada de caráter científico ou tecnológico ${ }^{26}$. A licitação pode ser dispensada na contratação de ICT, nos termos do art. 24, XXV da Lei ${ }^{\circ}$ $8.666 / 1993^{27}$, no entanto, como órgão da administração pública a ICT deve obedecer aos princípios da legalidade, impessoalidade, moralidade, publicidade e eficiência, conforme o art. 37, caput, da CF/1988. Nesse sentido, o edital previsto no art. $6^{\circ}$ da Lei de Inovação assegura a impessoalidade e equidade entre os concorrentes, em atendimento aos princípios da administração pública.

Cabe ao Estado promover e incentivar o desenvolvimento científico, a pesquisa e a capacitação tecnológica, nos termos do art. 218 da CF/1988 ${ }^{28}$. Os incentivos do Estado ao mercado interno devem se voltar ao desenvolvimento cultural e socioeconômico, o bemestar da população e a autonomia tecnológica brasileira, nos termos de lei federal ${ }^{29}$. A "lei federal" referida no art. 219 da CF/1988 somente foi positivada em 2 de dezembro de 2004, com a promulgação da Lei de Inovação e posteriormente com os benefícios fiscais instituídos pela Lei do Bem. Nesse contexto, a participação da ICT como órgão ou entidade da administração pública, representa o Estado como promotor da inovação tecnológica. Outras formas de atuação do Estado como "tomador de risco" na inovação tecnológica também estão previstas na referida Lei (por exemplo, subvenção econômica, meios de financiamento etc.).

Como visto nesta dissertação, a previsão constitucional de que lei apoiará as empresas que invistam em pesquisa, criação de tecnologia e o aperfeiçoamento de recursos humanos não significa que a intervenção do Estado na iniciativa privada é admitida ${ }^{30}$. O Estado não deve impor ao particular a obrigação de desenvolver, diretamente ou por intermédio de fontes externas de $\mathrm{P} \& \mathrm{D}$, as atividades de pesquisa tecnológica. Desse modo, cabe ao Estado, por intermédio de seus Ministérios, órgãos e agências, promover e apoiar a construção de ambientes especializados e cooperativos junto às empresas, ICTs, NITs, instituições de apoio e criadores.

\footnotetext{
${ }^{26}$ BRASIL, Lei ${ }^{\circ}$ 10.973/2004, Art. $2^{\text {o }}$, V.

${ }^{27}$ Vide modificação no art. 25 da Lei no $10.973 / 2004$.

${ }^{28}$ BRASIL, CF/1988, Art. 218.

${ }^{29}$ BRASIL, CF/1988, Art. 219.

${ }^{30}$ BRASIL, CF/1988, Art. $218 \S 4^{\circ}$.
} 
O desenvolvimento tecnológico é um desafio traçado para que a indústria brasileira consiga alavancar sua competitividade no âmbito do comércio internacional. Nesse sentido, o empresário brasileiro tem vislumbrado o processo inovador como uma alternativa para se diferenciar frente aos concorrentes nacionais e internacionais. Os resultados do PINTEC 2008 citados no Capítulo 3 comprovam essa tendência para a indústria e para os serviços selecionados, este último grupo que inclui as atividades relativas aos serviços de TICs e desenvolvimento de programas de computador.

A postura idealizada para o empresário brasileiro se coaduna com o perfil deste profissional na teoria de Joseph A. Schumpeter. De acordo com o economista, o empresário tem importância fundamental para a destruição criativa, também conhecida como fenômeno do processo inovador. O empresário, disposto a inovar, deve estar comprometido com a continuidade da empresa ao exercer atividade organizada para produção ou circulação de bens. O profundo conhecimento do empresário das nuances da organização de sua empresa e do mercado em que ela se insere capacita-o para corrigir falhas e identificar oportunidades estratégicas para alavancar a produção ou circulação de seus bens ou a prestação de seus serviços. Nesse sentido, pode-se afirmar que a demanda pela inovação surge no setor privado, junto às empresas ativas em cada setor da economia.

Corrobora com essa afirmação a dinâmica verificada com as empresas do setor de tecnologias da informação, cujo produto relevante para esta dissertação foi o software. A utilização dessas tecnologias é cada vez mais frequente em diversos contextos, especialmente, no âmbito das instituições que necessitam dessas soluções tecnológicas para suprir suas necessidades internas e organizar suas próprias atividades, tendo em vista o retorno econômico esperado com essas ações. Em suma, verificou-se que a demanda cada vez mais crescente por soluções tecnológicas tem sua origem em diversos segmentos de mercado.

Com base nos eixos da tríade da inovação tecnológica conceituada nesta dissertação (isto é, investimento, mercado e conhecimento), notou-se que o processo inovador no setor de TICs já detém fontes de investimento, concentradas em recursos públicos, já possui nicho de mercado, como mencionado em relação à demanda de soluções tecnológicas, porém, ainda encontra limitações ao conhecimento. É inquestionável que as redes informatizadas (por exemplo, a internet, intranet etc.) facilitaram o acesso às informações e com isso propiciaram meios alternativos para apropriação do conhecimento. $\mathrm{O}$ armazenamento das informações disponíveis, contudo, depende de um sujeito capaz de 
compreendê-las e cognitivamente as relacionar na forma de conhecimento. Portanto, o conhecimento pressupõe a existência de pessoas capazes de absorver informações e pensar sobre elas.

Para as empresas inovadoras, do grupo que inclui as atividades de tecnologia da informação e desenvolvimento de software, investigadas no âmbito da PINTEC 2008, a falta de mão-de-obra qualificada foi relacionada como o principal obstáculo para a inovação tecnológica. O histórico das políticas voltadas ao desenvolvimento do setor de informática no Brasil evidenciou que instituições de ensino de excelência nas áreas de engenharia já formavam profissionais altamente qualificados antes dos ciclos de programas governamentais de apoio a esse setor da indústria (por exemplo, ITA, Escola Politécnica etc.). Todavia, a indústria de informática brasileira não decolou e esse contingente de profissionais qualificados não se propagou na forma esperada, assim como não se inseriu na função de pesquisador no ambiente empresarial.

O conhecimento, portanto, foi preservado e também ampliado nos centros de pesquisa e instituições de ensino superior, sobressaindo-se desse grupo as universidades públicas. Dessa forma, a caracterização da ICT como universidade pública é muito positiva para a ocupação do terceiro eixo da tríade da inovação. Essas universidades são estruturadas sob a forma de autarquias e, portanto, são entidades da administração pública indireta. Assim, a contratação com essas instituições estão vinculadas ao regime do direito público, sendo aplicável, conforme o caso, as disposições da Lei de Inovação.

As universidades públicas, contudo, não têm por missão somente a pesquisa básica ou tecnológica, mas também o ensino e a extensão. As experiências das universidades públicas investigadas nesta dissertação (sendo elas, USP, UNICAMP, UFMG e UFRJ) através de seus NITs, no entanto, demonstrou que vem sendo possível conciliar a missão constitucional do ensino, pesquisa e extensão com a aplicação das políticas de gestão da propriedade intelectual e promoção da inovação tecnológica no ambiente universitário.

Diante dessas colocações, pode-se afirmar que a ICT, tendo em vista o seu objetivo para execução das atividades de pesquisa, está propensa a criar, enquanto a empresa deve estar disposta a inovar, ou seja, conceber ideias e colocar em prática o uso de criações intelectuais que transformem suas linhas de produção ou promovam suas vendas ou serviços. As parcerias de cooperação técnico-científicas previstas no art. $9^{\circ}$ da Lei de Inovação tendem a ser alternativas para conciliar os interesses do setor privado à missão 
institucional das $\operatorname{ICTs}^{31}$. De outro lado, a possibilidade, prevista no art. $8^{\circ}$ da Lei de Inovação $^{32}$, da ICT prestar serviços e a empresa "encomendar" a criação resultante da prestação dos serviços pela ICT é um modo de contornar as condicionantes da transferência de tecnologia ou licenciamento do uso, previstas no art. $6^{\circ}$ da referida Lei $^{33}$. Essas alternativas da Lei de Inovação, no entanto, pressupõem a existência de pessoal no setor privado capacitado a alocar soluções técnicas e criativas em projetos inovadores em cooperação ou sob a forma de "encomenda" com as ICTs. De fato, sem este contingente de mão-de-obra especializada as parcerias e as "encomendas" tendem a não sair do papel.

Nesse contexto, a conclusão desta dissertação resume-se na constatação de que a inserção de mão-de-obra qualificada no ambiente produtivo é a meta prioritária para a promoção da inovação tecnológica no setor de TICs, especialmente, em relação à indústria de software. No contorno desse desafio com o aproveitamento do conhecimento acumulado junto às ICTs, uma possível proposição de modificação da Lei de Inovação coaduna-se ao conceito de Entidade de Ciência, Tecnologia e Inovação (ECTI) extraída dos Projetos de Lei no 2.177/2011 e no 619/2011 em tramitação junto à Câmara dos Deputados e Senado Federal, respectivamente, ou seja, a incorporação da ICT privada como sujeito da Lei de Inovação ${ }^{34}$.

Desse modo, as contratações das empresas com ICTs não estariam sujeitas às normas do direito público, mas sim seriam regidas pelo direito privado. A publicação de edital nos contratos de transferência de tecnologia ou licenciamento de uso do programa de computador seria abandonada. A contratação poderia ser mantida sob sigilo desde a negociação até o início da exploração econômica do uso do software ou outro marco temporal ajustado entre a empresa e a ICT privada. Essas instituições privadas deveriam ter por escopo a prestação de serviços em atividades de P\&D\&I, sem fins lucrativos.

Com o propósito de estimular o desenvolvimento da indústria de software brasileira, o programa do software livre, isto é, licenciamento do uso do programa de

\footnotetext{
${ }^{31}$ BRASIL, Lei no $10.973 / 2004$, Art. $9^{\circ}$.

${ }^{32}$ BRASIL, Lei ${ }^{\circ} 10.973 / 2004$, Art. $8^{\circ}$.

${ }^{33}$ BRASIL, Lei no 10.973/2004, Art. $6^{\circ}$.

${ }^{34}$ De acordo com os Projetos de Lei Referidos, o conceito de ECTI é “órgão ou entidade pública ou privada, com ou sem fins lucrativos, legalmente constituída, que tenha por missão institucional, objetivo social ou estatutário, dentre outros, o desenvolvimento de novos produtos ou processos, com base na aplicação sistemática de conhecimentos científicos e tecnológicos e na utilização de técnicas consideradas avançadas ou pioneiras, ou execute atividades de pesquisa básica ou aplicada de caráter científico, tecnológico ou de inovacão, que seja beneficiária do fomento ou financiamento previsto nesta lei ;", (grifo nosso)
} 
computador de código aberto que permite o reproduzir e modificá-lo de acordo com os termos da licença ajustada, surge como uma opção promissora. Dentro do mesmo intuito, sugere-se a reformulação da indústria de software brasileira no sentido de abandonar o desenvolvimento tradicional de software produto para acompanhar a tendência mundial do setor de TICs de agregar serviços de alto valor agregado (por exemplo, consultoria, operação, manutenção e suporte técnico dentre outros) às licenças de programa de computador. Dessa maneira, a competição não se acirra no nível das grandes empresas que ostentam posições dominantes no mercado de software proprietário, mas sim se tira proveito de oportunidades para novos players no mercado que atendam as crescentes demandas por soluções tecnológicas.

Uma segunda proposição para solucionar as deficiências identificadas na articulação dos interesses da empresa e ICT, tanto pública como privada, seria a reformulação da sociedade de propósito específica prevista no art. $5^{\circ}$ da Lei de Inovação para que a participação minoritária nessas empresas possa ser tanto de origem pública como privada. É a oportunidade para propagação, em particular, do venture capital no setor de TICs.

Não se pretende com essas proposições esgotar a discussão sobre o tema proposto nesta dissertação. O processo inovador é dinâmico e de evolução contínua e a análise desenvolvida nesta dissertação procurou perseguir esse método, conservando-se em um ciclo ininterrupto de reflexões. 


\section{BIBLIOGRAFIA}

AGÊNCIA BRASILEIRA DE DESENVOLVIMENTO INDUSTRIAL - ABDI, Contribuições para a Política de Desenvolvimento Industrial, de Inovação e de Comércio Exterior: período 2011/2014. s.n. e s.l. p. 33. Disponível em http://www.brasilmaior.mdic.gov.br/wp-content/uploads/2011/09/livro.pdf. Acesso em nov., 2012.

AGHION, Philippe, GRIFFITH, Rachel. Competition and Growth: reconciling theory and evidence. Cambridge: MIT, 2005.

ARRUDA, Gustavo Favaro e CERDEIRA, Pablo de Camargo. Patentes de Medicamentos e Saúde Pública. Revista de Direito Mercantil, nº 139, jul-set 2005, pp. 189-201.

ASCARELLI, Tulio. Teoria de la concurrencia y de los bienes inmateriales. Barcelona: Bosch, 1970.

ASCARELLI, Tullio. O Empresário. Tradução de Fábio Konder Comparato. Revista de Direito Mercantil. n 109, p.183-189.

ASQUINI, Alberto. Perfis da Empresa. Tradução de Fábio Konder Comparato. Revista de Direito Mercantil. $n^{\circ}$ 104, p.109-126.

ASSOCIAÇÃO NACIONAL DE PESQUISA E DESENVOLVIMENTO DAS EMPRESAS INOVADORAS - ANPEI. Guia Prático de Apoio à Inovação. Ministério da Ciência e Tecnologia (MCT), 2009. Disponível em <http://proinova.isat.com.br/Downloads.asp>, acesso em 05 jun/2010.

BARBOSA, Cláudio R. Propriedade intelectual: introdução à propriedade intelectual como informação. Rio de Janeiro: Elsevier, 2009.

BARBOSA, Denis Borges (org.). Direito de inovação: comentários à Lei Federal de Inovação, Incentivos Fiscais à Inovação, Legislação estadual e local, Poder de Compra do Estado (modificações à Lei de Licitações). $2^{\text {a }}$ Ed. rev. e aumentada, Rio de Janeiro: Lumen Juris, 2011.

. Direito da Inovação: Comentários à Lei n. 10.973/2004, Lei Federal da Inovação. 2006. Juris, 2003.

. Uma Introdução à Propriedade Intelectual. $2^{\text {a }}$ Ed., Rio de Janeiro: Lumen

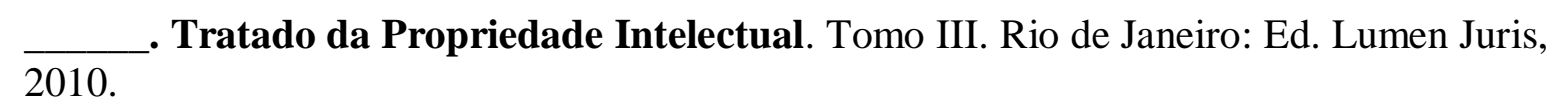
BASSO, Maristela. Propriedade Intelectual na Era Pós-OMC. Porto Alegre: Livraria dos Advogados, 2005. 
BASSO, Maristela; POLIDO, Fabrício; e RODRIGUES JR, Edson Beas (Orgs.). Propriedade Intelectual - Legislação e Tratados Internacionais. São Paulo: Atlas, 2007.

BERCOVICI, Gilberto. Ciência e Inovação sob a Constituição de 1988. Revista dos Tribunais. Ano 101, vol. 916, fev./2012. p. 267-295.

BERMAN, Marshall. Tudo que é Sólido Desmancha no Ar: a aventura da modernidade. Tradução: Carlos Felipe Moisés, Ana Maria L. Ioriatti. São Paulo: Companhia das Letras, 1996.

BRANDÃO, Vladimir; GONÇALVES, Ada Cristina V. et al. Brasil inovador : o desafio empreendedor : 40 histórias de sucesso de empresas que investem em inovação, Brasília: IEL - NC, 2006.

BRASIL, Ministério da Ciência, Tecnologia e Inovação - MCTI, Secretaria de Desenvolvimento Tecnológico e Inovação. MAGALHÃES, Fernanda Vanessa Mascarenhas (org.) Política de propriedade intelectual das instituições científicas e tecnológicas do Brasil: Relatório FORMICT 2011. Brasília, 2012. Disponível em: <http://www.mct.gov.br/index.php/content/view/8477.html>. Acesso em dez., 2012.

- Ministério da Ciência, Tecnologia e Inovação - MCTI. Política de propriedade intelectual das instituições científicas e tecnológicas do Brasil: Relatório FORMICT 2009. Brasília, 2010.2 Disponível em: <http://www.mct.gov.br/index.php/content/view/8477.html>. Acesso em dez., 2012.

- Ministério da Ciência, Tecnologia e Inovação - MCTI. Processo Produtivo Básico - PPB/ZFM. Disponível em: http://www.mct.gov.br/index.php/content/view/8688.html. Acesso em dez., 2012.

- Ministério do Desenvolvimento, Indústria e Comércio Exterior - MDIC. Conceito e breve histórico do PPB. Disponível em: http://www.desenvolvimento.gov.br/sitio/interna/interna.php?area=2\&menu=1103. Acesso em nov., 2012.

- Ministério das Relações Exteriores. Centro de Estudos das Sociedades de Advogados (CESA). Legal Guide for Foreign Investors in Brazil. Brasília: MRE: Brasil GlobalNet, 2012.

BOUÇAS, Cibelle. Empresas do Brasil adotam poucos incentivos à inovação, diz Whirlpool. Disponível em: http://www.valor.com.br/brasil/2893394/empresas-do-brasiladotam-poucos-incentivos-inovacao-diz-whirlpool . Acesso em nov., 2012.

CARVALHO, Sergio Medeiros Paulino; SALLES-FILHO, Sergio Luiz Monteiro e PAULINO, Sonia Regina. Propriedade Intelectual e a Dinâmica de Inovação na Agricultura. Revista Brasileira de Inovação, vol. 5, n. 2, jul./dez., 2006.

CASSIOLATO, José Eduardo et. al. Projeto Estudo Comparativo dos Sistemas de Inovação no Brasil, Rússia, Índia, China e África do Sul - BRICS, Brazilian Software 
Industry: a general view of its structure, specialization and competence building processes. Centro de Gestão de Estudos Estratégicos - CGEE. Rio de Janeiro, julho, 2007.

CERQUEIRA, João da Gama. Tratado da Propriedade Industrial. Vol. 1, Parte 1. Atualizado por Newton Silveira e Denis Borges Barbosa. Rio de Janeiro: Ed. Lumen Juris, 2010 .

CHESBROUGH, Henry. Open Innovation: A New Paradigm for Understanding Industrial Innovation. Oxford University Press, oct., 2006.

COLAIANNI, C. Alessandra; e COOK-DEGAN, Robert M. Columbia University's Axel Patents: Tecnology Transfer and Implications for the Bayh-Dole Act. Disponível em <www.ncbi.nlm.nih.gov/pmc/articles/PMC2750841>, acesso em maio/2010.

COLOMBO, Daniel Gama e. A Política Pública de Incentivo ao Setor de Informática no Brasil a partir da década de 90: uma análise jurídica. Dissertação (Mestrado em Direito) - Faculdade de Direito, Universidade de São Paulo, São Paulo, 2009.

COMPARATO, Fábio Konder . A Transferência Empresarial de Tecnologia Para Países Subdesenvolvidos: Um Caso Típico de Inadequação dos Meios Aos Fins. Revista de Direito Mercantil, Industrial, Econômico e Financeiro., nº 47, jul./set., 1982, p. 41-53.

CORIAT, Benjamin; e ORSI, Fabienne. IPR, Innovation and Public Interest. Is the new IPR regime enforced worldwide by the TRIPS sustainable? In: Econômica, vol. $10, \mathrm{n}^{\circ} 2$, Rio de Janeiro: Econômica, 2008. pp. 28-54.

CRISTONI, Inaldo. Polo de Inovação: Empreendedorismo Fervilhante. Valor Econômico, jun., 2011.

CRUZ, Carlos Henrique de Brito. e CHAIMOVICH, Hernan. Relatório UNESCO sobre Ciência 2010, UNESCO, 2010.

CRUZ, Liliam Ane Cavalhieri Da. O regime global da propriedade intelectual e a questão do desenvolvimento: o poder dos países em desenvolvimento no campo multilateral. Campinas, $2008.2 \quad$ Disponível em http://www.santiagodantassp.locaweb.com.br/br/arquivos/defesas/liliam.pdf, acesso em 19 jul/2011.

DI PIETRO, Maria Sylvia Zanella. Direito Administrativo. $18^{a}$ Ed., São Paulo : Atlas, 2005.

EVANS, Peter. Dependent Development: the Alliance of Multinational, State and Local Capital in Brazil. Princeton University Press, 2006.

FARINA, Elizabeth Maria Mercier Querido; AZEVEDO, Paulo Furquim; SAES, Maria Sylvia Macchione. Competitividade: mercado, estado e organizações. São Paulo: Singular, 1997.

FEKETE, Elisabeth Kasznar. O regime jurídico do segredo de indústria e comércio no direito brasileiro. Rio de Janeiro: Forense, 2003. 
FELÍCIO, César. Tecnologia aproxima UFMG das empresas. In: Valor Econômico, São Paulo, 02/03/2011. Disponível em <http://www.valoronline.com.br/impresso/primeirapagina/3021/392004/tecnologia-aproxima-ufmg-das-empresas $>$, acesso em fev/2011.

FERRAZ JUNIOR, Tercio Sampaio; MARANHÃO, Juliano de Souza de Albuquerque. Software livre: a administração pública e a comunhão do conhecimento informático. Revista de Direito Público da Economia - RPDE, Belo Horizonte, ano 3. n.11, p. 173 208, jul/set, 2005

FILHO, Calixto Salomão. Direito Concorrencial: as estruturas. São Paulo: Malheiros, 2007.

FINANCIADORA DE ESTUDOS E PROJETOS - FINEP. Brasil inovador: o desafio empreendedor. Brasília, 2006a. Disponível em <http://www.finep.gov.br/dcom/brasilinovador.pdf>, acesso em nov/2010.

FORGIONI, Paula A. Os Fundamentos do Antitruste. $2^{\text {a }}$ Ed., São Paulo, Revista dos Tribunais: 2005.

FREIRE, Emerson. Inovação e competitividade: o desafio a ser enfrentado pela indústria de software. Dissertação (Mestrado em Geociências). Universidade Estadual de Campinas, Instituto de Geociências, Campinas, SP: [s.n.], 2002.

FURTADO, Celso. Teoria e Política do Desenvolvimento Econômico. São Paulo, Editora Nacional, Biblioteca Universitária, Série 2a, Ciências Sociais, v. 24: 1967.

FURTADO, João. Padrões de Inovação na Indústria Brasileira. Disponível em: http://www.inovacao.unicamp.br/report/inte-art_furtado.pdf. Acesso em abr., 2012.

GARCIA, Balmes Vega. Direito e Tecnologia: contribuição ao estudo do regime jurídico da ciência, tecnologia e inovação. Tese de Doutorado. São Paulo: 2007.

GASPARINI, Diógenes. Direito Administrativo. 13ª ed., São Paulo: Saraiva, 2008.

GAVA, Rodrigo e VIDAL, Walderson João Rodrigues. Sistema de inovação em nível de firma: evidências de uma iniciativa no mercado brasileiro de telecomunicações. RACEletrônica, Curitiba, v. 3, $\mathrm{n}^{\mathrm{o}}$ 1, art. 10, p. 180-201, jan/abr., 2009. Disponível em http://www.anpad.org.br/rac-e. Acesso em set., 2012. p. 182.

GILBERT, Richard J. Competiton and Innovation. Competition Policy Center. In: Institute of Business and Economic Research, UC Berkeley, jan/2007. Disponível em $<$ http://escholarship.org/uc/item/9xh5p5p9>, acesso em 05 de jun/2010.

GOLD, E. Richard. Innovation and Productivity: the Need for an Intellectual Architect. Policy Options. Out., 2006. Disponível em http://www.cipp.mcgill.ca/data/publications/00000053.pdf (acesso 08/06/2010)

GOLDEMBERG, José. O fosso entre universidade e indústria. O Estado de São Paulo, São Paulo, $17 \quad$ jan/2011. Disponível em 
<http://www.estadao.com.br/estadaodehoje/20110117/not_imp667099,0.php>, Acesso em $26 \mathrm{jan} / 2011$.

GONÇALVES, Ada Cristina et al. Brasil inovador: o desafio empreendedor: 40 histórias de sucesso de empresas que investem em inovação. CARLOS GANEM e ELIANE MENEZES DO SANTOS (coord.), 2006.

GRANSTRAND, Ove. Innovation and Intellectual Property Rights. In: The Oxford Handbook of Innovation. Clarendon: Oxford University, 2005.

GRAU, Eros Roberto. A Reserva de Mercado, no Brasil, para a Produção de Bens de Informática, Revista da Faculdade de Direito da USP, v. 84/85, p. 204-217, São Paulo, 1989/1990. p. 205 e 206.

"Joint Ventures" e a Transferência de Tecnologia: Lei de Informática. Revista de Direito Mercantil, Industrial, Econômico e Financeiro, no 79 , São Paulo, ano jul./set., 1990, p. 8-15.

GRIZENDI, Eduardo. Manual de Orientações Gerais sobre Inovação. Ministério das Relações Exteriores, Projeto No. BRA/07/017 - Projeto de Promoção Comercial e Atração de Investimentos, p. 16-17 2011. Disponível em: http://download.finep.gov.br/dcom/manualinovacao.pdf. Acesso jul., 2012.

HAEFLIGER, Stefan, VON KROGH, Georg e SPAETH, Sebastian. Code Reuse in Open Source Software. Management Science, vol. 54, n. 1, jan., 2008, p. 180-193.

HOVENKAMP, Hebert. Innovation and the Domain of Competition Policy. Alabama Law Review. vol. 60, n 103, nov/2008, pp. 106.

IBGE. Classificação Nacional de Atividades Econômicas, CNAE 2.1. Disponível em: http://www.cnae.ibge.gov.br/secao.asp?codsecao=J\&TabelaBusca=CNAE_201@CNAE\% 202.1\%20-\%20Subclasses@0@cnaefiscal@0. Acesso em nov., 2012.

. O setor de tecnologia da informação e comunicação no Brasil: 2003-2006.

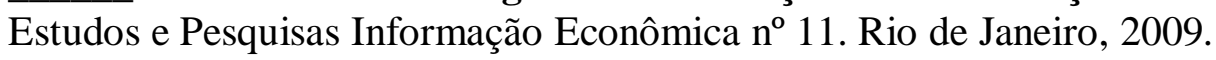

- Pesquisa de Inovação Tecnológica - PINTEC 2008, Instituto Brasileiro de Geografia e Estatística - Ministério do Planejamento, Orçamento e Gestão. Rio de Janeiro, 2010. Disponível em <http://www.ibge.gov.br/home/estatistica/economia/stic/default.shtm>, acesso em 11 jun/2011.

INTERNATIONAL EXPERT GROUP ON BIOTECHNOLOGY, INNOVATION AND IP. Toward a new era of Intellectual Property: From Confrontation to Negotiation. Montreal, set/2008. Disponível em 〈http://www.theinnovationpartnership.org/data/ieg/documents/report/TIP_Report_E.pdf >, acesso em 07 jun/2010.

JONES, Ivor. Open or Closed? Software for Development: the politics of software policy in Brazil and Argentina. 26th, April, 2010. Disponível em: 
http://xa.yimg.com/kq/groups/17397856/1337691932/name/100426+proposal++Ivor+Jones.pdf. Acesso em maio, 2012.

KATZ, Michael L., SHELANSKI, Howard A. Schumpeterian Competition and Antitrust Policy in High-Tech Markets. vol. 14, 2005. Disponível em <http://papers.ssrn.com/sol3/papers.cfm?abstract_id=925707>, acesso em 07 jun/10.

LANDES, William e POSNER, Richard. The economic Structure of intellectual property law. In: The Belknap Press of Harvard University Press. Cambridge, Massachussetts and London, England, 2003.

LANZANA, Antonio Evaristo Teixeira. Economia Brasileira: fundamentos e atualidade. São Paulo: Atlas, 2001.

LAPASTINA, Renata (Org.). Plano Nacional de Informática e Automação - Lei no 8.244/1991, II PLANIN. São Paulo: Letras \&Letras, 1992.

LEMOS, Ronaldo. Direito, tecnologia e cultura. Rio de Janeiro: Editora FGV, 2005.

LENHARI, Luciana Cristina e QUADROS, Ruy. Estratégias de Diversificação das Empresas de Telefonia Fixa frente à Convergência Digital nos Serviços de Telecomunicações - o caso Telefonica. Buenos Aires, Altec, $2007 . \quad$ Disponível em: http://www.extecamp.unicamp.br/gestaodainovacao/biblioteca/Lenhari Quadros ALTEC 2007 .pdf. Acesso jul., 2011. p. 3.

LEVIN, Richard D et al. Appropriating the Returns from Industrial Research and Development. In: Brookings Papers on Economic Activity, Washington: Brookings, 1987. Disponível em <http://www.jstor.org/pss/2534454>, Acesso em jun/2010.

LIPPOLDT, Douglas, STRYSZOWSKI, Piotr. Innovation in the Software Sector. OECD Publishing. Publicado em 8/dez/2009. Disponível em: http://www.keepeek.com/DigitalAsset-Management/oecd/science-and-technology/innovation-in-the-softwaresector_9789264076761-en. Acesso em nov., 2012. p. 8-9.

MANKIW, N. Gregory. Macroeconomia. trad. port. de A. B. Pinheiro de Lemos, orig.: Macroeconomics. 5a Ed., Rio de Janeiro: LTC, 2004.

MANSO, Eduardo Vieira. A informática e os direitos intelectuais, São Paulo, Revista dos Tribunais, 1985.

MARQUES, J.P Remédio. Propriedade Intelectual e Interesse Público. p. 318-354. Coimbra, Almedina, 2007.

MATIAS, Alexandre. Curtiu? Link, Estado de São Paulo, São Paulo, 2 de jan. de 2011. Disponível em http://blogs.estadao.com.br/link/curtiu/. Acesso em fev., 2011.

MATTOS, Paulo Todescan Lessa, ABDAL, Alexandre. O sistema jurídico-institucional de investimentos público-privados em inovação nos Estados Unidos. Revista de Direito Público da Economia - RDPE. Belo Horizonte, ano 7, n. 27, p. 181-201, jul/set, 2009. 
MATTOS, Paulo Todescan. O sistema jurídico-institucional de investimentos públicoprivados em inovação no Brasil. Revista de Direito Público da Economia - RDPE. Belo Horizonte : Fórum, ano 7, n⿳0 28, out/dez 2009.

O Novo Estado Regulador no Brasil: eficiência e legitimidade. São Paulo: Singular, 2006

MCAFEE, R. Preston, MIALON, Hugo M, WILIAMS, Michael A. Economic and Antitrust Barriers to Entry. Disponível em <http://vita.mcafee.cc/PDF/Barriers2Entry.pdf>, acesso em 29 nov/2010.

MCTI. 8.1.2 Dispêndios nacionais em pesquisa e desenvolvimento (P\&D) em relação ao produto interno bruto (PIB) de países selecionados, 2000-2010. Disponível em: <http://www.mct.gov.br/index.php/content/view/336625/Dispendios_nacionais_em_pesqui sa_e_desenvolvimento_P_D_em_relacao_ao_produto_interno_bruto_PIB_de_paises_selec ionados.html> Acesso dez., 2012.

MCTI. 8.1.7 Dotação orçamentária governamental em pesquisa e desenvolvimento (P\&D) de países selecionados, 2000-2011. Disponível em: <http://www.mct.gov.br/index.php/content/view/336713/Dotacao_orcamentaria_governam ental_em_pesquisa_e_desenvolvimento_P_D_de_paises_selecionados.html> Acesso dez., 2012

MEIRELLES, Helly Lopes. Direito administrativo brasileiro. 29a ed. São Paulo: Malheiros, 2004.

MELlo, Celso Antônio Bandeira de. Curso de Direito Administrativo. $28^{a}$ ed. São Paulo: Malheiros, 2011.

MOURA E SILVA, Miguel. Inovação, Transferência de Tecnologia e Concorrência: Estudo Comparado do Direito da Concorrência dos Estados Unidos e da União Européia. Coimbra: Almedina, 2003.

MOWERY, David C., NELSON, Richard R., SAMPAT, Bhaven N., ZIEDONIS, Arvids A. The growth of patenting and licensing by U.S. universities: an assessment of the effects of the Bayh-Dole act of 1980. Hamden: Elsevier. 1999.

NASSIF, Luis. Brasilianas. Org. Entrevista com Sérgio Rezende. Disponível em: http://www.advivo.com.br/materia-artigo/entrevista-sergio-rezende. Acesso em jan., 2011;;

NUNES, André Luis de Sá. Mudanças promovidas na lei de inovação nas funções e práticas de gestão dos intermediadores da cooperação universidade-empresa das universidades federais. Curitiba: UFPR, 2010. Disponível em <http://dspace.c3sl.ufpr.br/dspace/bitstream/handle/1884/23985/Dissertacao_AndreNunes UFPR.pdf?sequence=1.>, acesso em 21 jun/2011.

NUSDEO, Fábio. Curso de economia: introdução ao direito econômico. $4^{a}$ Ed., São Paulo: Revista dos Tribunais, 2005. 
ORGANIZAÇÃO PARA A COOPERAÇÃO E DESENVOLVIMENTO ECONÔMICO OCDE. Manual de Oslo: Proposta de Diretrizes para Coleta e Interpretação de Dados sobre Inovação Tecnológica. Tradução de Paulo Garchet. s.l: s.n.. Disponível em<http://www.mct.gov.br/index.php/content/view/4639.html $>$. Acesso em jun., 2010. p. 33-34.

- Manual de Frascati: Proposta de Práticas Exemplares para Inquéritos sobre Investigação e Desenvolvimento Experimental. Tradução de More than Just Words. $6^{\text {a }}$ ed. Coimbra: F-Iniciativas, nov., 2007. Disponível em <http://www.mct.gov.br/index.php/content/view/4639.html>. Acesso em jun., 2010

- Measuring Innovation: a new perspective, 2010. Disponível em: http://www.oecd.org/site/innovationstrategy/45183306.pdf. Acesso em jun., 2012.

- Convenção da OCDE (Convention on the Organization for Economic Cooperation and Development). Disponível em: http://www.oecd.org/general/conventionontheorganisationforeconomiccooperationanddevelopment.htm . Acesso em out., 2012.

ORRICO JR., HUGO. Pirataria de Software. São Paulo: Livros MM, 2004.

PEREIRA, Caio Mário da Silva. Instituições de Direito Civil: Contratos, vol. III. Rio de Janeiro: Forense, 2004.

PINDICK, Robert S. e RUBINFELD, Daniel L. Microeconomia. $7^{\text {a }}$ Ed., São Paulo: Pearson Education do Brasil, 2010.

POSSAS, Mario Luiz; FAGUNDES, Jorge; e PONDÉ, João Luiz. Política Antitruste: Um Enfoque Schumpeteriano. Ensaios sobre economia e direito da concorrência. São Paulo: Singular, 2002, pp. 11-31.

QUEIROZ, Marco Aurelio Lima de e VASCONCELOS, Flávio Carvalho. Inovação e Imitação na Indústria Farmacêutica: estratégias empresariais a partir da regulamentação dos medicamentos genéricos. Revista Brasileira de Estratégia - REBRAE, Curitiba, v.1, n.1, p. 107-18, jan./abr., 2008. p. 109.

REZENDE, Sergio Machado, VEDOVELlO, Conceição. Agências de financiamento como instrumento de política pública em ciência, tecnologia e inovação: o caso da Financiadora de Estudos e Projetos (Finep). Parcerias Estratégicas. Brasília, 2006. Disponível:em http://java.cgee.org.br/kmmsearch/download?doc=200806040111351.pdf $>$. Acesso em jun/2011.

ROCHA, Sergio André. Aplicação dos Incentivos à Inovação Tecnológica Previstos na Lei $\mathrm{n}^{\circ}$ 11.196/2005. Revista Dialética de Direito Tributário (RDDT), São Paulo, nº 171, p. 132-142, dez., 2009.

RODRIGUEZ, Alberto e DAHLMAN, Carl. Conhecimento e inovação para competitividade,original, Knowledge and Innovation for Competitiveness in Brazil. Brasília: Confederação Nacional da Indústria - CNI, 2008. 
ROPPO, Enzo. O Contrato. Coimbra: Almedina, 1988.

ROSCH, J. Thomas. Antitrust Regulation of Innovation Markets. ABA Antitrust Intellectual Property Conference. Berkeley/CA, 2009.

SACHS, Ignacy. Um projeto para o Brasil: a construção do mercado nacional como motor do desenvolvimento in BRESSER-PEREIRA, Luiz Carlos e REGO, José Marcio (Org.). A Grande Esperança em Celso Furtado. São Paulo: Ed. 34, 2001.

SAITO, Leandro. A "propriedade" intelectual como barreira à entrada de novos players no mercado de softwares. Biblioteca Eletrônica do Instituto Brasileiro de Propriedade Intelectual - IBPI, out., 2012. Disponível em: http://www.ibpibrasil.org/. Acesso em nov., 2012. p. 20

SAlAMA, Bruno M. e BENOLIEL, Daniel. Pharmaceutical Patent Bargains: The Brazilian Experience. 18 CARDOZO J. OF INT'L \& COMP. LAW 633, 2011. Disponível em: http://works.bepress.com/bruno_meyerhof_salama/45. Acesso em out., 2012.

. Towards an Intellectual Property Bargaining Theory: the Post-WTO Era, 32 U. PA. J. INT'L.L. 265 (2010). p. 32. Disponível em: http://works.bepress.com/bruno_meyerhof_salama/46/. Acesso em jun., 2011.

SALOMON, Marta. Investimento em inovação exige que FINEP vire banco, defende Mercadante. Disponível em: http://www.estadao.com.br/noticias/vidae,investimento-eminovacao-exige-que-finep. Acesso em jan., 2011

SALLES FILHO, Sergio et al. Avaliação de impactos da Lei de Informática: uma análise da política industrial e de incentivo à inovação no setor de TICs brasileiro. Revista da Inovação. Campinas, SP, 11, n. esp., p. 191-218, julho 2012.

SAMPAT, Bhaven N. The Bayh-Dole Model in Developing Countries: Reflections on the Indian Bill on Publicly Funded Intellectual Property. ICTSD Policy Brief, $\mathrm{n}^{\circ}$ 5, out/2009.

SAMUELSON, Pamela. Innovation and Competition: Conflicts over Intellectual Property Rights in New Technologies. In: Science, Technology, \& Human Values, vol. 12, $\mathrm{N}^{\mathrm{o}}$ 1, Washington: Sage Publications, Winter 1987. Disponível em <http://www.jstor.org/stable/688813>, acesso em 13 mar/2010.

SANTOS, Laymert Garcia dos. Politizar as novas tecnologias: o impacto sociotécnico da informação digital e genética. São Paulo: Ed. 34, 2003.

SANTOS, Manoel Joaquim Pereira. A Proteção Autoral de Programas de Computador. Rio de Janeiro: Lumen Juris, 2008.

SANTOS, Marli Elizabeth Ritter dos, TOLEDO, Patricia Tavares Magalhaes de, LOTUFO, Roberto de Alencar (org.). Transferência de Tecnologia: estratégias para a estruturação e gestão dos Núcleos de Inovação Tecnológica. Campinas, SP: Komendi, 2009. 
SARTI, Fernando e LAPLANE, Mariano F. O Investimento Direto Estrangeiro e a internacionalização da economia brasileira nos anos 90, p. 11-57 in LAPLANE, Mariano, COUTINHO, Luciano e HIRATUKA, Célio. Internacionalização e desenvolvimento da indústria no Brasil. Campinas: UNESP, 2004. p. 12 e 15.

SCHUMPETER, Joseph A. Capitalism, Socialism, and Democracy. Harper Perennial Modern Thought, New York: First, 2008.

- Capitalismo, Socialismo e Democracia. Rio de Janeiro: Editora Fundo de Cultura, 1965.

SCOTCHMER, Suzanne. Innovation and Incentives. Cambridge: MIT, 2004.

SECRETARIA DE POLÍTICA DE INFORMÁTICA - SEPIN. Tecnologia da Informação: A Legislação Brasileira, $7^{\mathrm{a}}$ Ed. revista e ampliada, Brasília : Ministério da Ciência e $\quad$ Tecnologia, $2010 . \quad$ Disponível em <http://www.mct.gov.br/index.php/content/view/32784.html $>$, acesso em nov/2010.

SEGAL, Ilya, WHINSTON, Michael D. Antitrust in Innovative Industries. The American

Economic Review, vol. 97, $\mathrm{N}^{\mathrm{o}}$ 5, Dec. 2007. Disponível em <http://www.jstor.org/stable/30034581>, acesso em 13 mar/2010.

SILVA, Alexandre Pacheco da. Antes de uma Fundação, um Conceito: Um Estudo sobre a disciplina jurídica das fundações de apoio na cooperação entre Universidade e Empresa. Dissertação (Mestrado em Direito) - Escola de Direito de São Paulo, Fundação Getúlio Vargas, São Paulo, 2011.

SILVA, José Afonso da. Comentário Contextual à Constituição. São Paulo: Malheiros, 2005.

. Curso de Direito Constitucional Positivo. 32a ed. São Paulo: Malheiros, 2009.

SILVA, Maria Carolina Gontijo da. O Conceito de Inovação Tecnológica e os Benefícios Fiscais Instituídos pela Lei $\mathrm{n}^{\circ} 11.196 / 2005$, Revista Dialética de Direito Tributário (RDDT), São Paulo, p. 83-89, nº 199, abr., 2012. P. 83

SILVEIRA, Newton. Propriedade Intelectual: propriedade industrial, direito de autor, software, cultivares. $3^{\text {a }}$ Ed., Barueri: Manole, 2005.

Propriedade intelectual: propriedade industrial, direito de autor, software, cultivares, nome empresarial. $4^{\mathrm{a}}$ ed., Barueri, SP: Manole, 2011.

. A Proteção legal do "Software", Revista dos Tribunais, ano 74, vol. 596, p. 2230, jun., 1985

. Direito de Autor no Design. 2 2a ed, São Paulo: Saraiva, 2012.

SOARES, José Carlos Tinoco. Patentes de programas de computador, Revista ABPI, $\mathrm{n}^{\mathbf{o}}$ 20, jan./fev., 1996, p. 39-46. 
SOLOW, Robert M. Perspectives on Growth Theory. The Journal of Economic Perspectives, vol. 8, n 1 (Winter, 1994), pp. 45-54. Disponível em: http://links.jstor.org/sici?sici=0895-

3309\%28199424\%298\%3A1\%3C45\%3APOGT\%3E2.0.CO\%3B2-J. Acesso em out., 2012.

SUTTON, John. Sunk Costs and Market Structure. cap. 1-3. Cambridge: MIT, 1992.

TAVARES, André Ramos. Ciência e Tecnologia na Constituição. Revista de Informação Legislativa, ano 44, $\mathrm{n}^{\mathbf{0}}$ 175, Brasília: Subsecretaria de Edições Técnicas do Senado Federal, jul./set., 2007.p.11.

$\begin{array}{lrrrrr}\text { Parecer jurídico } & \text { ao caso } & \text { sob consulta } & \text { referente à Ação } & \text { Direta de } \\ \text { Inconstitucionalidade } & \mathrm{n}^{\text {o }} & & 1.923-5 / \mathrm{DF} & \text { Disponível } & \text { em }\end{array}$ http://www.cgee.org.br/noticias/parecerandre.pdf . Acesso em set., 2012.

TEDESCHI, Patrícia Pereira. Inovação Tecnológica e Direito Administrativo. Dissertação (Mestrado em Direito) - Faculdade de Direito, Universidade de São Paulo, São Paulo, 2005.

TIDD, Joe, BESSANT, John, PAVITT, Keith. Gestão da Inovação. Trad. De Elizamari Rodrigues Becker et al. $3^{\text {a }}$ ed. Porto Alegre: Bookman, 2008.

TIGRE, Paulo, MARQUES, Felipe Silveira. Apropriação tecnológica na economia do conhecimento: inovação e propriedade intelectual de software na América Latina. Economia e Sociedade, Campinas, v. 18, nº 3 (37), p. 547-566, dez., 2009. p.548.

TIMM, Luciano Benetti. O Novo Direito Contratual Brasileiro. Rio de Janeiro: Forense, 2008.

UNCTAD-ICTSD. Resource Book on TRIPS and Development. New York: Cambridge, 2005.

UNIVERSITY OF CALIFORNIA. The Bayh-Dole Act A Guide To The Law And Implementing Regulations. Disponível em <http://www.ucop.edu/ott/faculty/bayh.html\#FN10>, acesso em 21 jun/2011.

VASCONSELlOS, Marco Antonio S. e GARCIA, Manuel E. Fundamentos de Economia. São Paulo: Saraiva, 2003.

VERSPAGEN, Bart. Innovation and Economic Growth Theory - A Schumpeterian Legacy and Agenda. Cambridge: Cambridge University, 2007.

ZIEDONIS, Rosemarie H. Intellectual Property and Innovation. John Wiley \& Sons Ltd. 2008 . 